\title{
A CONSTRUÇÃO DA TEMPORALIDADE NO TEXTO MULTIMODAL
}

\author{
(The construction of temporality in multimodal text)
}

\author{
Audria Leal ${ }^{1}$ \\ (Centro de Linguística da Universidade Nova de Lisboal \\ Fundação para a Ciência $e$ Tecnologia)
}

\begin{abstract}
This paper aims to study the construction of grammatical category temporality in multimodal text. For this, we analyze the textual genre cartoon from three portuguese newspapers: Diário de Notícias, Público and Correio da Manhã. For this analysis we follow the theoretical proposals of Social Semiotics, the Socio-discursive Interactionism and Theory of the Predicative and Enunciative Operations. The results indicate that the language meanings are constructed from the social practices to meet the communicative function of the genre.
\end{abstract}

Keywords: multimodal text, types of discourse, textual genre, temporality, social semiotics and sociodiscursive interactionism.

\section{RESUMO}

Este artigo tem o objetivo de estudar a construção da categoria gramatical temporalidade no texto multimodal. Para isso, analisamos o gênero textual cartoon retirados de três jornais portugueses: Diário de Notícias, Publico e Correio da Manhã. Para esta análise, nós seguimos as propostas teóricas da Semiótica Social, do Interacionimo Sociodiscursivo e da Teoria Formal Enunciativa. Os resultados indicam que os significados da língua são construídos a partir das práticas sociais, para atender a função comunicativa do gênero textual.

Palavras-chave: texto multimodal, tipos de discurso, gênero textual, temporalidade, Semiótica Social e Interacionismo Sociodiscursivo.

\section{Introdução ${ }^{2}$}

Neste artigo, assumimos que os textos são multimodais, porque convocam não só produções verbais orais ou escritas, mas também outras unidades semióticas. Em consequência, ao analisar textos, devemos considerar também a análise destas unidades semióticas. De fato, nos estudos linguísticos sobre os textos e os gêneros, quando a dimensão icónica ou não verbal é raramente considerada, as análises tendem a ter um olhar limitativo sobre o objeto estudado. Com o advento de novas tecnologias, não é possível ignorar que a

\footnotetext{
${ }^{1}$ Investigadora do Centro de Linguística da Universidade Nova de Lisboa. Integra a equipe do Grupo Gramática \& Texto. É doutora em Linguística - Teoria do Texto, tendo vindo a publicar trabalhos no domínio da Linguística Aplicada, Linguística do texto e do discurso, no qual privilegia o quadro teórico e metodológico do Interacionismo Sociodiscursivo, da Semântica Enunciativa e a da Semiótica Social.

${ }^{2} \mathrm{O}$ presente trabalho foi financiado por Fundos Nacionais através da FCT - Fundação para a Ciência e Tecnologia (Portugal), no âmbito do projeto UID/LIN/03213/2013.
} 
sociedade incorpora cada vez mais o visual nas suas ações comunicativas. Esta incontornável realidade faz sobressair o carácter multimodal dos textos, no qual o não verbal cada vez mais interage com o sistema da língua. Assim, entender o processo desta interação acrescenta esclarecimentos significativos sobre o funcionamento da linguagem em sociedade.

Ciente desta problemática, este artigo tem como objectivo analisar a construção da categoria gramatical temporalidade e refletir sobre o seu papel na organização discursiva do texto multimodal. Como o presente trabalho procurará ter em consideração as duas dimensões - verbal e não verbal, procuraremos perceber as inter-relações que se estabelecem entre estas duas dimensões e como estas inter-relações interferem na componente discursiva e, consequentemente, na construção do valor temporal. Para atingir este objetivo, escolhemos analisar textos do gênero cartoon $^{3}$. Reconhecidamente multimodal, a escolha de analisar o cartoon foi determinada como exemplo que permiti verificar, a partir da sua natureza aglutinadora, a influência cada vez maior da imagem (ou outros modos semióticos) nos textos produzidos nas sociedades modernas. Aliás, é importante referir que existem cartoons apenas com o não verbal, não sendo possível existir cartoons sem imagem. Ou seja, é um gênero reconhecido, essencialmente, pelo visual.

Temos por base epistémica o quadro teórico-metodológico do interaccionismo sociodiscursivo (daqui pra frente ISD) proposto por Bronckart (1999; 2008). Como complemento deste quadro e no sentido de aprofundar a análise da temporalidade, recorreremos à Teoria Formal Enunciativa proposta por Culioli (1990) e por Campos (1997). E por se tratar de um texto multimodal, adotaremos também o quadro teórico da Semiótica Social proposto por Kress \& van Leeuwen (1996/2006), nomeadamente a proposta metodológica que se encontra na obra Reading Images: The Grammar of Visual Design.

Face ao exposto e no intuito de atingirmos o nosso objetivo, este artigo será apresentado em três partes: num primeiro momento, centrar-nos-emos na apresentação do quadro teórico do ISD, procurando efetuar uma inter-relação tanto com a Teoria Formal Enunciativa como com a Semiótica Social; na segunda parte procuraremos mostrar como se dá a organização temporal no gênero textual cartoon a partir do estudo da sua organização discursiva; e para terminar, concluiremos ao verificar de que forma esta organização é utilizada pelo autor do texto como estratégia para a construção do humor. Além disso, partilhamos do pensamento de

\footnotetext{
${ }^{3}$ No Brasil, o cartoon apresenta mais duas subdivisões: a charge e a tira cómica. Cartoon é o mesmo que Cartum. Essa segunda forma é adotada na escrita do português do Brasil, a partir de 1964. Para este artigo, utilizaresmos a grafia do Português Europeu: cartoon.
} 
Possenti (2005) quando afirma que o humor é também elaborado linguisticamente. Por isso, acreditamos que os valores temporais fazem parte da criação do efeito para o humor.

Para isso, iremos trabalhar com cartoons recolhidos em três dos jornais de maior circulação em Portugal, a saber: Público, Diário de Notícias e Correio da Manhã. Como resultado da nossa análise, esperamos contribuir para um estudo em que se congregam os elementos linguísticos e não-verbais, verificando a forma como eles se articulam nos textos para uma construção de significados, atendendo, inclusive a função social dos gêneros textuais.

\section{A construção da temporalidade: do texto às unidades microlinguísticas}

Ao focalizar o texto como ação responsável pela interação humana, estamos seguindo as tendências atuais nos estudos da linguagem (cf. Koch, 1997). Nestas perspectivas, podemos citar o ISD e a Semiótica Social como teorias convergentes, pois ambas partem de uma noção de texto como prática social. Além disso, as duas correntes observam que a língua, enquanto construção social, congrega características de acordo com as práticas sociais, tendo a sua realização em textos empíricos, a partir de algum modelo de gênero.

De facto, para Bronckart (1999, p.69), o texto é entendido como atividade global da comunicação que define, em grande parte, as propriedades e os conjuntos de relações a serem observados, incluindo aquelas de domínio gramatical. Para Kress, Leite-Garcia \& van Leeuween (1997, p.259), o foco da Semiótica Social é a textualidade. Esta linha teórica procura observar a relação entre o contexto social e a produção e a leitura de textos multimodais. Além disso, a Semiótica Social assume que a construção dos significados do texto multimodal surge a partir das relações entre os diferentes elementos presentes no texto. A partir destes dois pontos de vista, podemos concluir que a relação entre o texto e suas unidades são determinadas pela diversidade das práticas sociais. Este é um posionamento basilar que sustenta a nossa pesquisa. Esse posicionamento é relevante para observar dois dos aspectos que se relacionam e que são fundamentais: primeiro, todas as formas de construção de significado serão perspectivadas a partir do uso da linguagem e da sua inscrição social, histórica e ideológica e, em segundo, a função comunicativa, derivada da prática social, estará subjacente às escolhas do produtor textual, desde a escolha do gênero até os itens textuais, incluindo os aspectos microlinguísticos. 
Esta última asserção está assente na perspectiva teórica do ISD. De fato, Bronckart (2008) propõe um modelo de análise de textos o qual postula que as operações psicológicas realizadas por um agente (produtor textual), quando se depara com dada situação de ação de linguagem (produção de um novo texto), determinam não só a escolha do gênero como a própria arquitetura textual. Esta arquitetura é composta por três níveis hierarquizados e interativos à semelhança de um folhado textual. As três camadas deste folhado são a infraestrutura geral do texto; os mecanismos de textualização e os mecanismos enunciativos. É na infraestrutura que encontramos a organização discursiva: os tipos de discurso (discurso interativo, discurso teórico, narração e relato interativo). Podemos definir tipos de discurso “como configurações particulares de unidades e de estruturas linguísticas" (Bronckart, 2006:148) que entram nas composições dos textos e que são resultantes das operações psicológicas denominadas de mundos discursivos.

Os mundos discursivos são criados pela atividade de linguagem. Eles "organizam as relações entre as coordenadas do mundo vivido do agente, as de sua situação de ação e as dos mundos construídos coletivamente" (Bronckart, 2006, p.148). Esses mundos discursivos são construídos com base em dois subconjuntos de operações: as primeiras referem-se à relação existente entre as coordenadas que organizam o conteúdo temático da produção textual e às coordenadas do mundo real do produtor; as segundas esclarecem o relacionamento das diferentes instâncias de agentividade (personagens, grupos, instituições, etc.) e sua inscrição espaço-temporal com os parâmetros físicos da ação da linguagem em curso (agente-produtor, interlocutor e espaço-tempo da produção).

Para o ISD (Bronckart, 1999), um dos parâmetros que caracteriza os tipos de discurso é a relação entre as coordenadas temporais dos processos verbalizados no texto e as coordenadas temporais da situação de produção (imediata ou encenada), a qual temos acesso por meio de marcas linguísticas ou por imagens como é o caso do gênero cartoon. Esta relação evidencia se as coordenadas que organizam o conteúdo temático são explicitamente marcadas à distância das coordenadas gerais da situação de produção, então teremos um processo de disjunção; ou, se não é marcada à distância, e então teremos um processo de conjunção. Outro parâmetro que caracteriza os tipos de discurso é a relação entre as instâncias de agentividade verbalizadas no texto e o produtor textual, ou seja, se há ou não implicação do produtor na ação de linguagem. Neste caso, quando o produtor não se implica na ação de linguagem, teremos um processo de autonomia, ou, caso contrário, falamos em implicação quando o 
produtor se implica no texto. Em resumo, estas operações de implicação/autonomia e de conjunção/disjunção vão dar origem a quatro tipos de discurso: o discurso interativo (implicação e conjunção), discurso teórico (autonomia e conjunção), relato interativo (implicação e disjunção) e narração (autonomia e disjunção).

Sendo a construção da temporalidade um dos parâmetros determinante para as operações psicológicas (mundos discursivos) semiotizadas pelos tipos de discurso, assumimos a posição de Bronckart (1999) quando este afirma que a temporalidade é marcada pela relação entre o momento da produção e o momento temporal expresso pelo verbo ou por outras formas que marcam uma temporalidade.

Neste sentido, a Teoria Formal Enunciativa (daqui para frente TFE) proposta por Culioli (1990) e também por Campos (1997) pode aprofundar o entendimento das operações subjacente aos tipos de discurso. Esta teoria apresenta um modelo de funcionamento geral da linguagem que demonstra o processo de construção de significação. De fato, para esta teoria, "a significação de um enunciado, ou de um conjunto de enunciados, resulta da inter-relação dos valores construídos na enunciação" (Correia \& Pereira, 2015, p.51). Para Culioli (1990), o enunciado é o resultado de operações abstratas que incidem sobre uma determinada forma linguística, localizando este acontecimento linguístico em relação à situação de enunciação $\left(\mathrm{Sit}_{0}\right)$, na qual congrega os parâmetros de Sujeito da enunciação $\left(\mathrm{S}_{0}\right)$ e do Tempo-espaço da enunciação $\left(\mathrm{T}_{0}\right)$. Vale ressaltar ainda que o conceito de enunciado, subjacente a este estudo, "deve ser entendido como um agenciamento de formas, marcadoras de operações abstratas (CULIOLI, 1990). Essa conceção de enunciado afasta-se, assim, de enunciado enquanto manifestação de um ato de fala" (Correia \& Pereira, 2015, p.51).

Ainda com relação à construção da temporalidade ou dos valores temporais, podemos afirmar que estes valores são construídos a partir de processos que são marcados tanto pelos tempos verbais quanto pelos advérbios temporais. Estes marcadores vão localizar o acontecimento linguístico em relação à situação de enunciação $\left(\mathrm{Sit}_{0}\right)$. Assim, para a TFE, o enunciado é o resultado das operações de localização que incide sobre a relação predicativa. Sobre as operações de localização, é importante salientar que algumas operações possuem como termo localizador o parâmetro T (tempo), resultando assim em valores referenciais de tempo e aspecto; enquanto outras apresentam o parâmetro $S$ (sujeito-enunciador) como termo localizador. Neste último caso, cabem as operações de modalização. 
Segundo Campos \& Xavier (1990, p.301-302), o parâmetro tempo que é associado ao acontecimento linguístico, o tempo $\mathrm{T}_{2}$, possui um valor resultante da operação que o localiza em relação a $\mathrm{T}_{0}$, sendo este $\mathrm{T}_{0}$, como já referido, o parâmetro localizador tempo da situação de enunciação que indica o momento da enunciação. Esse valor de $\mathrm{T}_{2}$ "pode ser de anterioridade, simultaneidade e posteridade em relação ao $\mathrm{T}_{0}$ ”. Outra categoria gramatical que pode ser associada à análise do tempo e, consequentemente, aos tipos de discurso, é o aspecto. $\mathrm{O}$ valor aspectual refere-se ao modo como o acontecimento é construído na língua, concernente a sua configuração microtextual, "e não apenas à sua localização cronológica" (op. Cit.). Esse acontecimento pode ser estruturado como perfectivo, quando o intervalo é fechado, isto é, a sequência de instantes temporais é construída como um todo fechado (evento que já aconteceu); ou imperfectivo, quando o acontecimento é descrito como estando ainda a decorrer $\left(\mathrm{T}_{3}\right)$. O tempo e o aspecto são considerados como categorias distintas. No entanto, para um estudo da temporalidade na percepção dos tipos de discurso, elas podem ser associadas para um melhor entendimento tanto do processo de conjunção ou disjunção, como de implicação e autonomia.

\section{A construção da temporalidade e a Semiótica Social}

A Semiótica Social surge na década de 80 , com inspiração na concepção do signo de Ferdinand Saussure. Essa escola tem como pressupostos teóricos a Linguística SistêmicoFuncional de Halliday (1979), agregando, igualmente, a Análise Critica do Discurso (ACD), com o objetivo de fornecer ferramentas para a análise de textos multimodais. A noção de signo desenvolvido pela Semiótica Social tem como eixo basilar a célebre noção de signo de Saussurre, na qual o signo é composto por dois componentes: um formal, que será o significante; e um de conteúdo, conhecido como significado. Contudo, para Saussure (2000), segundo os pressupostos do Cours de Linguistique Générale (Cours), a relação entre o significado e o significante é arbitrária, e, ao mesmo tempo, estática. ${ }^{4} \mathrm{Ou}$ seja, apesar de não existir correlação entre os dois componentes do signo, há uma relação de pertença, não havendo, segundo o Cours, escolha ou intenção.

\footnotetext{
${ }^{4} \mathrm{O}$ que parece ser arbitrário em Cours (Cours de Linguistique Générale), não é o arbitrário que encontramos na leitura de Saussure no Ecrits (Ecrits de Linguistique Générale), publicado em 2002 (cf. Leal, 2011, p. 171).
} 
Nesse ponto, a semiótica social distingue-se de Saussure ao assumir que, na verdade, esta relação entre significante e o significado é uma relação motivada socialmente tal como confirma a citação abaixo:

In our view signs are never arbitrary, and motivation should be formulated in relation to the sign-marker and the context in which the sign is produced, and not in insolation from the act of producing analogies and classifications. Sign-markers use the forms they consider apt for the expression of their meaning, in any medium in which they can make signs. 5

(Kress \& van Leeuwen, 2006:08)

Por outro lado, podemos afirmar que a motivação gerada pelas práticas sociais também é entendida no Ecrits por Saussure (2002:277) quando afirma "la langue n'est créée qu'en vue du discours ${ }^{6}$ ". Portanto, para Saussure, o discurso é, segundo o esclarecimento de Bronckart (2008:34), de um lado, "realização da potência da língua, mas, de outro, ele alimenta constantemente essa potência, que não existiria ou que desapareceria sem ele". Neste mesmo sentido, pomos em evidência que para a Semiótica Social, segundo Pimenta \& Santana (2007:155-156), “a língua não é somente uma representante das práticas sociais, mas, também, um instrumento capaz de influenciar, criar e transformar a realidade social".

É de referir que a relação motivada entre o significante e o significado dependerá do posicionamento social do indivíduo. Certamente, quando falamos de interação, podemos concluir que o significado será preenchido pelos participantes no momento da interação. Isto faz com que o signo não tenha um significado fixo, mas que seja construído socialmente. É nesta construção que o signo obtém diferentes significações, tanto quanto forem possíveis os contextos sociais em que ele pode estar inserido. A partir deste pensamento, podemos concluir que os indivíduos produzem e reproduzem significações a partir do mundo social em que se situam. Estas significações são expressas na linguagem a partir de diferentes modos semióticos não apenas da ordem do linguístico, mas também pelo visual. É com base nesta perspectiva que a Semiótica Social elabora o seu quadro de análise denominado de Grammar of Visual Design.

\footnotetext{
${ }^{5}$ Tradução livre "Em nossa perspectiva, os signos nunca são arbitrários, e a motivação devia ser formulada em relação com o signo-marcador e com o contexto no qual este signo é produzido e não isolada do ato de produzir analogias e classificações. Os signos-marcadores usam as formas que eles consideram aptas para expressar o seu significado, em qualquer meio nos quais eles possam fazer signos."

${ }^{6}$ Essa é apenas uma primeira frase de uma importante citação em que Saussure discorre sobre a relação língua e discurso.
} 
A gramática visual tem como objetivo fornecer uma gramática que também contemple os significados realizados pelo visual, procurando interpretar experiências e formas de interação social dentro de uma perspectiva semiótica. Para isso, os autores Kress \& van Leeuwen (2001) retomam as três metafunções propostas por Halliday (1985), interpessoal, ideacional e textual na gramática sistêmico-funcional e as aplicam às análises de textos multimodais. Deste modo, Kress \& van Leeuwen (1996/2006) concebem outras três (meta)funções distintas que serão denominadas de significados, são elas: a representacional, interacional e composicional. Como o foco do presente artigo é a temporalidade, iremos evidenciar apenas o primeiro significado: o representacional. É nesta categoria que cabe os processos que indicam alguma marca de temporalidade do ato semiótico.

O significado representacional indica o que está sendo apresentado pela cena comunicativa, quais as relações que estão sendo construídas entre os elementos apresentados e em quais circunstâncias. Há dois tipos de representações na imagem: as narrativas e as conceituais. As primeiras podem ser identificadas por meio de setas imaginárias (vetores) que apontam para um movimento dentro do ato semiótico. Estes condutores indicam existir um participante que direciona a sua ação para o outro. Isto gera um efeito de estarmos a visualizar ações, eventos ou processos de mudança. Já as representações conceituais caracterizam os participantes em termos da sua classe, estrutura ou significação. Este tipo de representação é marcado por imagens que trazem características de efeito estático, ao contrário da ação que encontramos na representação narrativa.

Kress e van Leeuwen (1996/2006) colocam a dimensão temporal inserida no processo analítico da representação conceitual. Para os autores, a característica principal é o fato de mostrar o ato semiótico como sendo realizado ou situado em um tempo traçado numa espécie de linha imaginária. Nessa perspectiva mais restrita, a temporalidade será apresentada por marcadores que fazem alusão a um tempo visivelmente demarcado. Numa perspectiva mais ampla, podemos considerar a temporalidade como um processo perceptível também na representação narrativa. Isto é possível se o ato semiótico fizer alusão a algum atributo que revele o tempo, conjugando o conceitual e o narrativo. No entanto, não existem vetores nos processos analíticos, sendo a temporalidade indiciada apenas pelas características estáticas e sendo interpretados como atributos que revelam o tempo. 


\section{A construção da temporalidade no texto multimodal: o gênero cartoon}

No gênero cartoon, é a parceria imagem mais linguagem verbal que cria os parâmetros da situação de ação da linguagem em curso, trazendo informações sobre personagens, grupos ou instituições e sua relação com o contexto em que estão inscritos. Este gênero traz assuntos políticos e sociais da atualidade, com temas que são considerados opiniões dos autores expressados de forma satírica. Por isso, podemos dizer que expressar uma opinião que tenha um efeito humorístico sobre um tema da atualidade é a função comunicativa deste gênero. Além disso, verifica-se que o cartoon faz parte da atividade jornalística, uma vez que é publicado em jornais ou revistas, mas também pode ser considerado como uma ação de linguagem pertencente à atividade lúdica.

Vejamos, então, a análise dos cartoons abaixo:

\section{Cartoon 1}

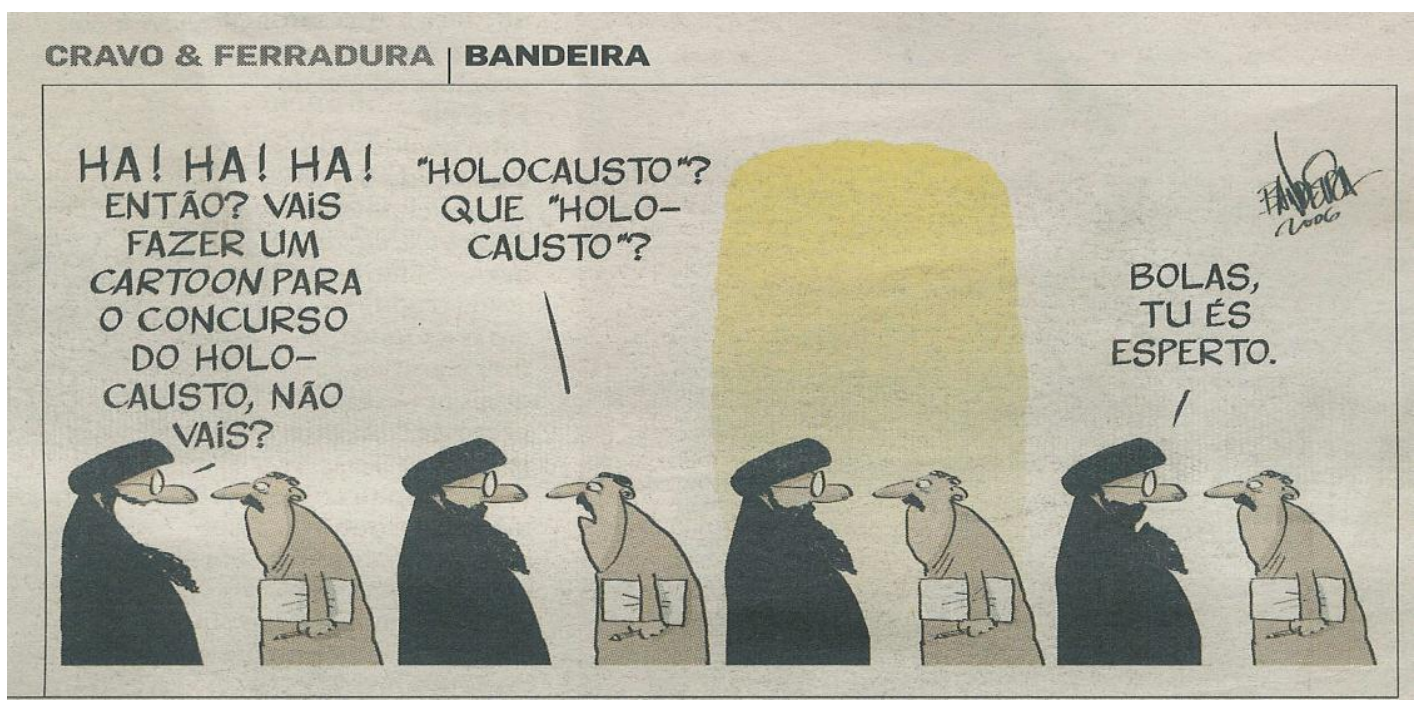

Fonte: Diário de Notícias, 15/02/2006

A temática do cartoon 1, acima destacado, faz referência à publicação, na Dinamarca, de cartoons sobre Maomé, que foram alvo de críticas por parte de religiosos islamitas, gerando grande polêmica. ${ }^{7} \mathrm{O}$ autor do cartoon traz o conteúdo temático do mundo real dos interactantes e o coloca no texto de modo encenado. Assim, para ser compreendido, é necessário que os leitores tenham conhecimento dos parâmetros ligados a esse mesmo

\footnotetext{
${ }^{7}$ A publicação de imagens de Maomé, profeta e líder espiritual do Islão, é considerada pecado e blasfêmia pela religião Muçulmana.
} 
conteúdo temático encenado, sendo para isso interpretado segundo os preceitos válidos no mundo real do leitor. No caso do exemplo 1, a encenação é feita por meio de uma réplica de uma conversa entre dois interactantes. Neste diálogo, conjugam-se os parâmetros de implicação e conjunção próprios do discurso interativo (DI), uma vez que, por meio da encenação dos turnos de fala, temos acesso às marcas linguísticas do tipo de discurso característico de produção textual em contexto imediato. Além disso, através da imagem, conhecemos não só os produtores desses diálogos representados, como também temos acesso à sua situação de produção física e social, o que reforça a presença do discurso interativo.

Na primeira encenação de fala, destacamos como marcas da presença do discurso interativo a onomátopéia "ha! ha! ha!", que representa uma risada; a marca conversacional então?, com valor de interpelação; e a presença da oração interrogativa, do tipo tag (cf: Mira Mateus et al, 1989, p.477), Vais fazer um cartoon para o concurso do holocausto, não vais?. Embora a tag seja aqui utilizada como uma estratégia manipulatória em que se tenta levar o co-enunciador a responder ou confirmar aquilo que era pretendido pelo enunciador, a resposta do parceiro não é a "esperada". Pelo contrário, o personagem com o caderno na mão lança outra pergunta, Holocausto? Que Holocausto?, o que gera "estranheza", sendo esta idéia confirmada pela falta do verbal ao manifestar, no terceiro quadro, o silêncio. No caso de cartoons em que o plano de texto é dividido por quadros ou segmentos, o último quadro será caracterizado por assinalar o que Possenti (2005) chamou de "gatilho" do humor. Assim, no fecho o Bolas, tu és esperto, o personagem justifica o seu espanto inicial ao detectar, na resposta do outro, uma estratégia para desqualificar os efeitos do Holocausto. De fato, no mundo fundamentalista Islâmico, essa estratégia é utilizada por diferentes facções islamitas. $\mathrm{Na}$ época da publicação de cartoons sobre Maomé na Dinamarca, os líderes islâmicos também fizeram um concurso de cartoons com o tema do Holocausto (tema considerado tabu tanto para os judeus, como para o ocidente, no geral), como retaliação aos cartoons de Maomé. No mundo atual, ambos os temas (Holocausto e Maomé) são "sagrados" (nesse sentido usado como um assunto sério em que não se aceita socialmente o "fazer humor"). Nesse fecho, o autor coloca em evidência a própria discrepância entre negar o Holocausto e fazer dele assunto para os cartoonistas.

Além da dimensão praxiológica referida no parágrafo anterior (opinar com humor), o que queremos aqui também sublinhar é a construção dos valores temporais que marcam a implicação. Além do uso da interrogativa do tipo tag, pois o esperar uma resposta imediata 
por parte do parceiro da interação, caracteriza-se como uma das marcas de implicação e conjunção do discurso interativo, outra marca linguística que reforça a identificação do DI, é o uso da forma verbal vais fazer, com valor de futuro próximo. Esta é uma forma perifrástica do futuro (ir+infinito) que assinala um movimento para realizar a ação em um tempo posterior (aqui próximo da simultaneidade). Nesse caso, o intervalo do verbo é aberto à direita e fechado à esquerda, o que mostra um movimento do presente para a posterioridade (futuro). Outras duas formas de se notar a semiotização do DI são: a flexão verbal aponta para a presença da segunda pessoa do singular (tu), marcando a implicação de agentividade; e também a marca conversacional bolas, típica de diálogos.

As marcas manifestadas pelo não verbal, além de mostrarem representações narrativas (a risada, o olhar um para o outro, o segurar papel e lápis), também há representação conceitual realizada pela identificação da vestimenta dos personagens e do material que transportam. De fato, o desenho apresenta dois personagens, que reconhecemos pelas suas vestimentas e pelos seus traços físicos tratar-se de religiosos islamitas a conversarem. A partir disso, surge o reconhecimento do papel social dos interlocutores (dois agentes de uma mesma religião), e também a representação do lápis e papel que nos leva a supor tratar-se de um cartoonista. Assim, podemos afirmar que é combinação da representação narrativa e conceitual que fornece inferências para a constituição do conteúdo temático por parte do leitor. O uso da representação narrativa mostra que estamos a assistir uma conversa no momento presente e a representação conceitual marca a identidade dos interactantes e a sua representação em termos do que significam ou do que são. 


\section{Cartoon 2}

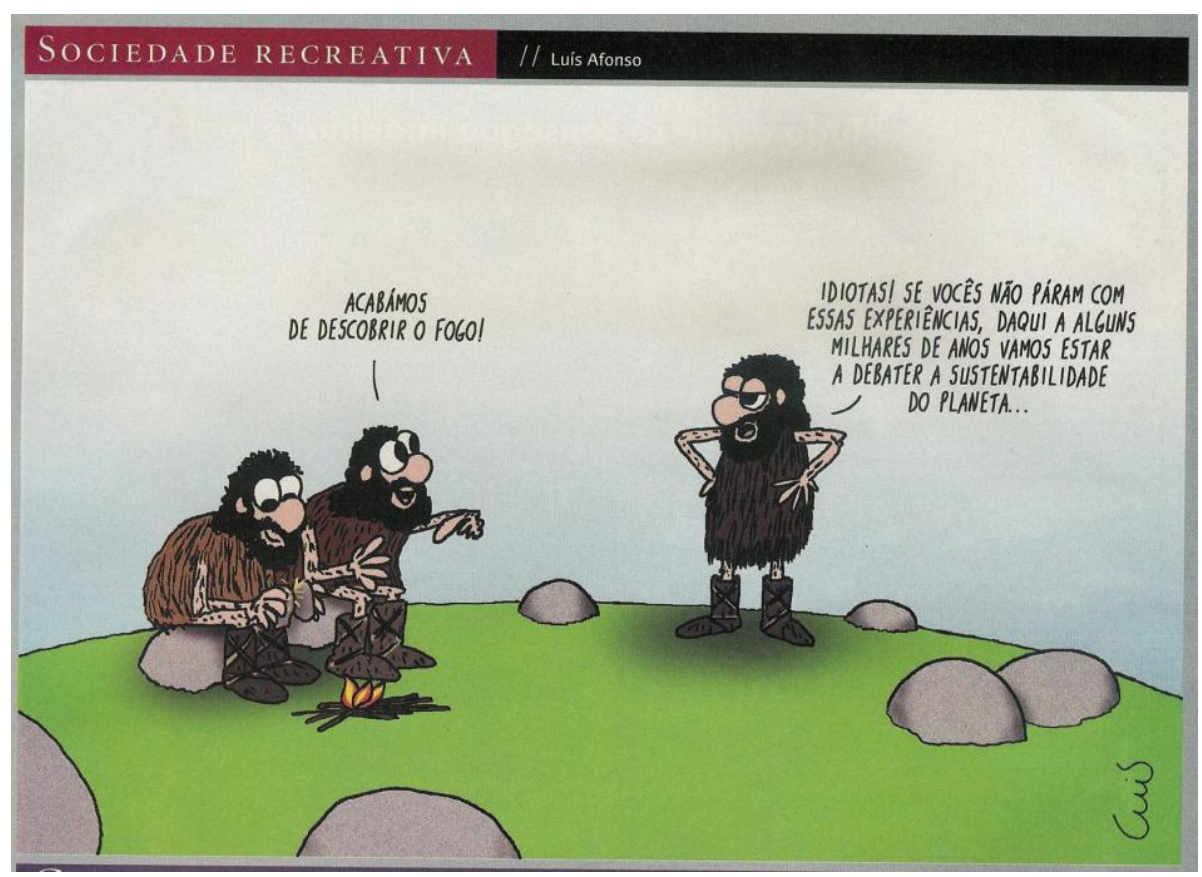

Fonte: Público, 29/01/2006

O cartoon 2, ao contrário do anterior, é configurado em um único quadro. Contudo, também apresenta uma encenação de um diálogo entre os personagens, na qual conjugam-se os parâmetros de implicação e conjunção próprios de textos que trazem uma encenação de turnos de fala. No caso do cartoon, tal como mostramos no exemplo anterior, sabemos quais os produtores desses diálogos representados e qual a situação de produção física e social encenada. Isto mostra que a imagem aliada às marcas linguísticas reforça a presença do discurso interativo. Com relação à construção dos valores temporais que vão marcar a conjunção, temos na primeira fala, Acabámos de descobrir o fogo!, uma construção temporal no passado, mas com valor de ação terminada no presente. Isto é perceptível não só pela construção pretério perfeito + verbo no infinitivo, como e principalmente pelo próprio significado semântico da construção acabar de, que revela uma ação terminada no instante atual. Este reforço do presente continua na segunda fala, Idiotas! Se vocês não param com essas experiências, daqui a alguns milhares de anos vamos estar a debater a sustentabilidade do planeta..., na qual irá aliar a conjunção do verbo no presente, param, com a implicação do interactante estabelecida pelo pronome vocês, como marca de $2^{\circ}$ pessoa. Além disso, a construção do futuro próximo ir+infinitivo, vamos estar a debater, indica uma ação situada no presente continuada pelo futuro. Aliada a esta construção, temos o localizador 
temporal, daqui a alguns milhares de anos, que reforça a ideia de construção no presente que se prolonga pelo tempo como uma linha temporal.

$\mathrm{O}$ visual produz os significados representacionais narrativo e conceitual. O significado narrativo é apresentado pela ação de acender uma fogueira com pedras, como se fazia no tempo pré-histórico. O significado conceitual é construído a partir das característcas físicas: traços físicos e indumentárias que significam homens pré-históricos. A interação desses dois tipos de representação cria uma figuração temporal do passado. $O$ que contrasta com o presente e futuro assinalado pelas marcas linguísticas. Com isso, podemos afirmar que é a combinação da representação narrativa e conceitual que fornece inferências para a constituição do conteúdo temático por parte do leitor, procurando recriar uma situação temporal passada localizada na pré-história. O cartoonista brinca com o leitor ao relacionar um tema da atualidade, a sustentabilidade do planeta, o que é reproduzido não só pelo léxico, mas também pelo movimento temporal do texto (do presente para o futuo), com a criação da representação da pré-história. A temática deste cartoon é construída com base na percepção da discrepância temporal. É o constraste entre a imagem e o texto verbal responsável por criar o efeito de humor e atender à função do gênero.

\section{Cartoon 3}

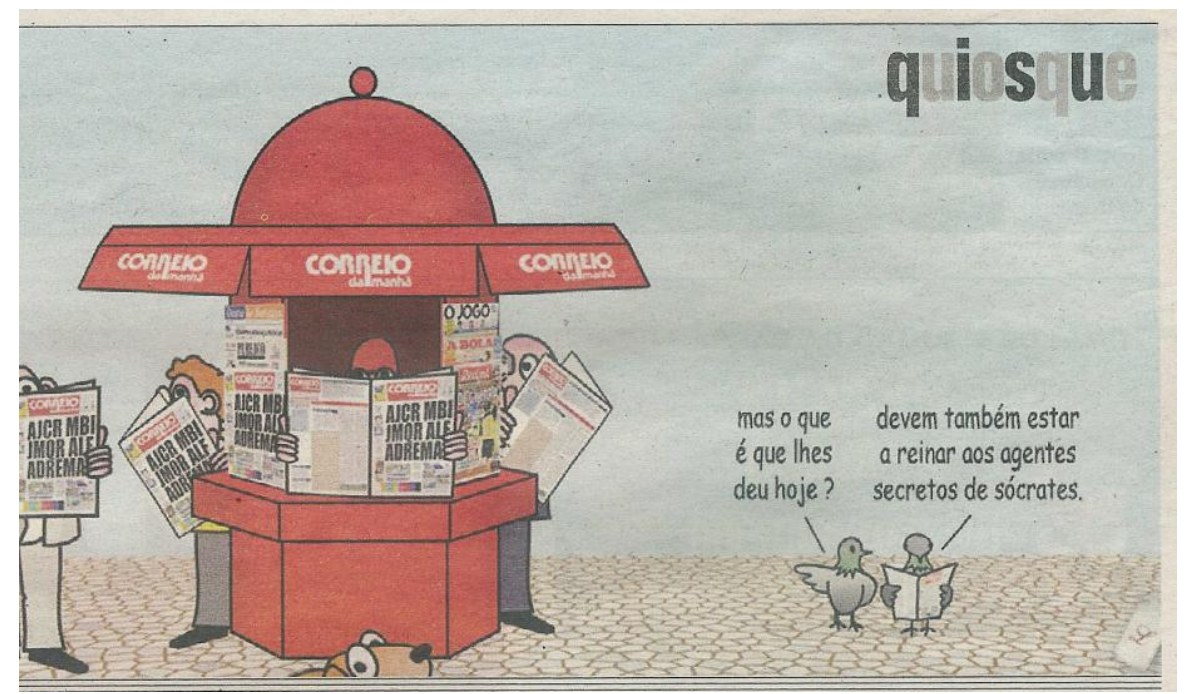

Fonte: Correio da Manhã, 03/02/2006

No cartoon 3, assim como nos dois exemplos anteriores, temos a encenação de um diálogo. Neste exemplo, o discurso interativo aparece na primeira fala, marcado pela oração interrogativa, mas o que é que lhes deu hoje?. A temporalidade é expressa pela presença da 
forma verbal no pretérito perfeito simples deu mais o deíctico hoje. A combinação deu hoje revela um valor temporal de anterioridade, mas é incluída entre os dois limites de duração, apontando para uma localização de simultaneidade, em uma construção de presente. Esta questão é reforçada quando analisamos o deíctico hoje, pois, este possui no texto um papel central. Para a semântica, o hoje expressa um corte que divide o tempo em dois momentos que se opõem: um ontem, passado, e um outro, amanhã , futuro. Tendo, assim, um valor de simultaneidade, porque a indicação do hoje refere-se ao momento em que é feita a pergunta. Desse modo, há uma relação temporal conjunta à da ação de linguagem que também pode ser relacionada à data da publicação do cartoon. A resposta do outro participante na interação, devem também estar a reinar de agente secreto do Sócrates, configura-se como um fecho para o texto. A construção verbal, devem estar, mostra um valor modal epistémico associado à possibilidade. Desse modo, nesta resposta, temos a construção de uma sugestão de ação que está em curso no hoje, ocorrendo um valor temporal relacionado à construção devem estar. Queremos ainda destacar o papel do advérbio também nesta oração, uma vez que se relaciona com o fazer de duas ações; a primeira é indicada pela imagem, leitura do jornal; a segunda é expressa pelo verbal, ser espião do Sócrates. Na série de cartoons conhecida como quiosque, É frequente haver leituras de jornal (inclusive pelos pássaros), mas é inusitada a falta de comentários sobre a notícia lida por parte dos personagens humanos, levando-nos a concluir que o fato de todos estarem a ler o jornal é um disfarce para melhor recolherem informações secretas para serem transmitidas ao primeiro ministro da época, Sócrates. O uso do também estabelece uma relação direta entre o verbal e o não verbal, que só é possível entender através do funcionamento anafórico desse advérbio quando observamos a imagem. Ainda com relação à conclusão, acreditamos tratar-se do discurso teórico, uma vez que a agentividade é expressa pelo uso implícito da terceira pessoa do plural, [eles] devem. Contudo, encontramos um exemplo do DT que é do tipo não puro, já que o nome próprio Sócrates refere-se ao primeiro ministro de Portugal, no ano de 2006, configurando-se como uma marca de implicação do mundo real do leitor na ação de linguagem.

Com relação aos processos realizados pela imagem, do lado esquerdo, vemos os personagens a lerem as notícias, enquanto do lado direito os pássaros fazem o comentário, ao mesmo tempo que lêem o jornal. Este quadro apresenta uma representação narrativa: leitura do jornal, apontar e conversar. Nesse caso, apesar de a imagem mostrar o pássaro com o jornal aberto, que pela imagem vemos que se trata de pombos, pois são os pássaros típicos das 
praças públicas, o processo verbal não se caracteriza como a leitura de uma notícia jornalística, mas como a resposta a uma pergunta. $\mathrm{O}$ tema desse cartoon tem relação com as escutas telefónicas obtidas a partir de conversas de determinados políticos. Este caso revelou que algumas personalidades conhecidas do país tinham os seus telefones sob escuta sem o seu consentimento (procedimento conhecido, no Brasil, como grampear o telefone). Quando este caso foi levado a público, houve acusações de que teria sido o primeiro ministro a dar a ordem de "grampear os telefones", embora tal possibilidade seja inverossímil, pois o telefone do próprio Sócrates também havia sido grampeado.

\section{Notas conclusivas}

Segundo Cadet, Charles \& Galus (2002, p.52), o cartoon apresenta um texto verbal e traços (que podem ser aqui expressos como imagens) desenvolvidos a partir de uma situação da atualidade. Reconhecido como um gênero jornalístico, tem a intenção de provocar o riso do leitor, sendo, por isso, conhecido como um texto que traz uma opinião em forma humorística, mesmo que o tema decorre de uma situação trágica, ou mesmo que o assunto seja considerado tabu. Podemos falar de um gênero em tríade, no qual três elementos são essenciais: a imagem, o humor e temas sociais e políticos. Estes três elementos são parte do gênero como características que marcam a sua "personalidade" e que possibilitam o seu reconhecimento pelos interlocutores.

De facto, essas três características vão estar em constante interação, formando os parâmetros que influenciam a organização textual, possibilitando a ação do gênero na sociedade e também o agir do cartoonista pelo seu texto. Os pârametros da organização textual que vão desde o desenho até os aspectos mais microlinguísticos vão interagir no sentido de responder às questões como a caracterização funcional do gênero no uso sóciohistórico da língua e de que forma essa caracterização aparece estabilizada na realização textual.

É o que constatamos a partir da análise de um dos aspectos da língua, a categoria gramatical temporalidade. Isto é, os componentes organizativos do cartoon funcionam em interação, servindo como sistema de instruções, apresentando as referências do mundo vivido pelo produtor que é semelhante ao do leitor e com o qual este irá encontrar caminhos suficientes para chegar à construção das ideias satirizadas pelo cartoonista. Assim, tal como procuramos mostrar, a língua em sua dimensão semiótica é construída a partir das práticas 
sociais dos indivíduos, é responsável pela interação humana e para atender os propósitos comunicativos. Assim a língua configura como o modo pelo qual é possível construir e transformar a realidade social.

Recebido em: março de 2016 Aprovado em: maio de 2016 audrialeal@fcsh.unl.pt

\section{Referências bibliográficas}

BRONCKART, J-P. Genre de textes, types de discours et "degrés" de Langue. In: Revue Texto! Janvier, vol. XIII, $\mathrm{n}^{\mathrm{o}}$ 1, 2008. Disponível em: http://www.revuetexto.net/docannexe/file/86/bronckart_rastier.pdf. 2008.

BRONCKART, J-P. Atividade de linguagem, discurso e desenvolvimento humano. In: Anna MACHADO, A.R. \& MEIRELLES, M. L. (orgs). Campinas: Mercado de Letras, 2006.

BRONCKART, J-P. Atividades de Linguagem, Textos e Discursos. Por um Interacionismo Sócio-discursivo. São Paulo: Editora da PUC-SP, EDUC, 1999.

CADET, C; CHARLES, R \& GALUS, J,-L. La communication par l'image. France: Nathan, $2^{\mathrm{a}}$ ed, 2002.

CAMPOS, Mª H. C. Tempo, aspecto e modalidade. Porto: Porto Editora, 1997.

CAMPOS, M ${ }^{\mathrm{a}}$ H. C. \& XAVIER, M ${ }^{\mathrm{a}}$ F. Sintaxe e Semântica do Português. Lisboa: Universidade Aberta, 1991.

CORREIA, C. N. \& PEREIRA, S. Formas e Construções Linguísticas no Português Europeu: Ferramentas Referenciais e Gênero Textual. Cadernos de Linguagem e Sociedade. Brasília (DF): Thesaurus Editora, 2015. Vol 16 (1), p.48-60.

CULIOLI, A. Pour une linguistique de l'énonciation: opérations et représentations. Paris: Ophrys, 1990.

COUTINHO, M. A. (2006 b). O texto como objecto empírico: consequências e desafios para a linguística. Veredas 10 (1-2). Disponível em: http://www.revistaveredas.ufjf.br/volumes/veredas_portugal/artigo07.pdf

COUTINHO, M. A. (2005). Para uma linguística dos géneros de texto, Diacrítica 19/1, Braga: Universidade do Minho.

KRESS, G. \& VAN LEEUWEN, T. Reading Images: The Grammar of Visual Design. London: Routledge. $2^{\mathrm{a}}$ ed, 2007. 
KRESS, G; LEITE-GARCIA, R. \& VAN LEEUWEN, T. Discourse Semiotics. In: Van Dijk, T. (ed.). Discourse as Structure and Process: Studies a Multidisciplinary Introduction. Série Discours: Sage Publication, vol 1, 1997, p. 257-291.

LEAL, A. A organização textual do género cartoon: aspectos linguísticos e condicionamentos não linguísticos. Tese de doutoramento. Lisboa: FCSH-UNL, 2011. Disponível em: http://run.unl.pt/handle/10362/6646

MIRA MATEUS, M.H. et al. Gramática da Língua Portuguesa. Lisboa: Editorial Caminho, 1989.

PIMENTA, S. M. O. \& SANTANA, C. D. A. Multimodalidade e semiótica social: o estado da arte. In: MATTE, A.C.F. (org.). Lingua(gem), texto, discurso: entre a reflexão e a prática. Lucerna: Rio de Janeiro, $2^{\mathrm{a}}$ vol, 2007, p. 152-174.

SAUSSURE, F. Curso de Lingüística Geral. 22ª ed. São Paulo: Cultrix, 2000.

SAUSSURE, F. Écrits de linguistique générale. Paris: Gallimard, 2002. 